\title{
The Reform of English Teaching Situation and Practice of University Based on the Theory of Constructivism
}

\author{
Zhiyun Chen ${ }^{*}$
}

Foreign Language Department, Hunan University of Science and Engineering, Yongzhou City, Hunan, 425199, China

\begin{abstract}
Since twentieth Century 90 years, Constructivism Based Virtual Learning Environments (VLE) has been a hot topic in the field of educational technology learning environment research. However, since 2004, with the rapid development of all kinds of social software Web2.0 technology, coupled with the advent of the era of knowledge explosion and the pursuit of personalized learning (Personalized), in the face of the era of knowledge of digital learning new appeal and the social demands for talents, in the rich tools, rich resources of today, how should we the reform of learning, to try to diversification and individuation in professional development, and the self can successfully molded in various fields and the practice of industry elite? Such a society, the individual is faced with a variety of network learning environment, it more uncertain. But the only and can be determined, is to establish their own side of the learning environment, that is, personal learning environment. Since 2004 the personal learning environment (PLEs) concept since the spread of PLEs in China, is still in its infancy, but the theoretical model and practical application and operation of small, is also not mature enough. All of the above considerations, the research and the ecological trend of thoughts on Education (PLEs is one) increasing effect. This paper mainly carried out the following research work. First of all, through the analysis of elements and functions of PLEs is introduced; secondly, from the point of view of the study of metaphor, PLEs construction process of the analysis, to explore the basic principles, the theoretical model and the main form of PLEs construction, and puts forward concrete strategies accordingly; finally, selecting the right PLEs construction case, according to the interview of his depth and learning tracking, sort out the successful learning experience, in order to test the validity and rationality of the PLEs construction model and strategies.
\end{abstract}

Keywords: Ecology, learning, model, personal learning environments, strategy.

\section{INTRODUCTION}

From the agricultural age to the industrial age, from the information age to the knowledge age, the creation of human beings in their own time to switch to go further, along the way. Along with the technology bring us second times of human evolution, the global information sharing and interaction of the speed and scale of the unprecedented level. According to the British scholar James Martin (James Martin) statistics, the doubling time of human knowledge is different in different period: in nineteenth Century doubled every 50 years, twentieth Century is doubled every 10 years, and is currently is doubling every 3 years. Today we can know knowledge is half 10 years ago did not know (Gonzalez, 2004). The research on PLEs originated in the virtual learning environment VLE (Virtue Learning Environment), began in the 90's of last century, and has been concerned and the development in the early twenty-first Century. In PLEs the whole development process, it has received much attention in foreign countries, have been widely studied, also made some achievements relatively mature. Specifically, we can be summarized as the following two aspects: 1) the theoretical significance of the PLEs analysis and PLEs model construction and development direction of the debate. 2) the theory of PLEs analysis and the concept of the importance of PLEs to the mainstream, and most of the characteristics of the new information era Web2.0, on how to use all kinds of social software to build PLEs aspects thoroughly. On the development trend of PLEs, experts in the field also have my own view and opinion, the future development of PLEs such as Wide PLEs, Open Web, described in detail the relevant articles in the visible. The PLEs model construction, mainly around the Stephen Downes, Ray Sims, Mark van Harmelen, Graham Attwell, Scott Wilson to create PLEs programs, and try to related applications. 2) the practice of PLEs Technology (including software and web site development and design of Web2.0). The author mainly based on the following [1-4], combing the development of technology. In 1998, the learning environment research group released the first version of the FLE Media Lab in Helsinki (Future Learning Environment--- Fle3 later), it is the history of PLEs. In 2000, Oleg Liber (from the The University of Bolton) has released the first P2P learning system, called Colloquia, which can be referred to as the PLES of the first inflection point.

In 2004, Robot Coop released 43Things website, is a watershed in the PLEs study in the true sense; in February, the pebble learning and Woolwich Hampton University jointly issued the first version of the interface of PebblePad based on Flash (originally called PACE (personal, academic, academic and industry)); in March, Dave Tosh and 
Ben Werdmuller development and release the Elgg personal learning system; in November, "personal learning environment" the academic term was first recorded in the JISC / CETIS conference[5-8]. In 2006, The University of Bolton's personal learning environment project group has released a test version of PLEsX, which is divided into two versions, one is the network version of the use of LifeRay entrance, the other is a desktop software based on Eclipse. In 2007, Mark Van Harmelen and his team has released MPLES (Manchester PLEs) in the two new version [9]. In 2009, Dokeos released the Dokeos version of the test, the PLEs focused on the investigation of the notebook computer, the conditions of individual learning, and personalized testing tool [10]. This study will be based on the ecological perspective, referring to PLEs, learning ecology (Ecology of Education) and the latest research results, in the basic concept and basic theory of the subject to find support, discusses the theory model of personalized, ecological construction of PLEs and specific strategies, and to verify the research of them, to look forward to the final they can be modified and perfected.

\section{WHAT IS THE PERSONAL LEARNING ENVI- RONMENT?}

To better understand the PLEs, learning environment is the first important concept that we should grasp the. What is the learning environment?

The earliest study of learning environment is the United States educational technologists Knirk.F.G, which in 1979 will be defined as: "the learning environment consists of the study area school buildings, library, classroom, laboratory, playground and the family learning sites" [11]. Since twentieth Century since the 90 's, the learning environment as a kind of new teaching metaphor, domestic and foreign scholars are concerned about it, and the understanding and definition of it made a lot of efforts (Wilson, 1995; Brush\&amp;Saye, 2000; Jonassen, 1999; He Kekang, 2003; to Zhiting, 2002; Chen Qi, 2003; Zhong Zhixian, 2005) [1214]. Especially after the birth of constructivism, learning environment is to expand and expand the connotation.

\subsection{The Core Concept of Personal Learning Environ- ment}

Since 2004 since the spread of the concept of the PLEs, the domestic and foreign scholars on what is done a lot to explore PLEs, "some people think that the PLEs is more of a concept and not a specific tools, but there are a lot of people think that the principle of PLEs can be a tool of software (such as PLEX) to present [15]," but so far there is no unified conclusion. A PLEs does not define a uniquely determined, currently in the research community are respected, the definition used by Stephen, it will PLEs described as "loose a collection of tools, services, and resources, is the use of a new mode of network power". PLEs can be summarized as follows: 1) PLEs is not a specific object (such as a tool, and more mixture) is a new concept of learning time to be born. 2) PLEs can be regarded as a complex system, should use "to the analysis of its concept" system, mainly composed of people, resources, tools and services and other factors. 3) PLEs were allowed to study the individual customized learning objectives, selection of learning tools, control, management and study experiences, distributed cognition, to construct the meaning of knowledge.

\subsection{The Theoretical Basis of Personal Learning Envi- ronment}

The concept of distributed cognition (Distributed Cognition) is a new paradigm of rethinking cognitive phenomenon in all fields, clearly put forward by Hutchins et al. In general, distributed cognition theory mainly wants to convey to the people: the cognitive process of human behavior is to break the shackles and limitation of individual, group and by others, the intervention of artificial products distribution of the environment. With this new cognitive perspective to re-examine the study, we can see more clearly the specific difference. Relevance theory is a learning theory for the digital age. The PLEs have been as a theoretical basis, here is mainly because the birth and relevance theory of PLEs with the same background, namely the development of Web2.0 technology and the widespread use of. Therefore, research on the PLEs Association of constructivism, meaningful. Situated cognition (situated cognition) is a kind of research method, it spans many subjects and objectives, involves the knowledge and action of neural, behavior, social, psychological point of view. With the development and popularization of Web2.0 technology, the Internet has become more and more and more people choose to "learning field", into the very easy to neglect to the real situation of the study, and used in the actual gap. The famous scholars in the field of study motivation, USA psychologist Keller (Keller), he thinks "refers to the learners' motivation to achieve the established objectives, can decide the experience or escape experience, and in the relevant aspects of the effort and persistence". In PLEs, we think that motivation management is such a process, as shown in Fig. (1). Knowledge management is a new management discipline, was first applied in the business areas of the economy, it has absorbed the essence of many subjects and perfected continuously in practice. As a kind of management culture, knowledge management has already exists, however, as a kind of thought of knowledge management, and consciously used by humans, or in recent years. What is knowledge management, let us from a "knowledge management formula" image to interpret and understand it, as shown in Fig. (2).

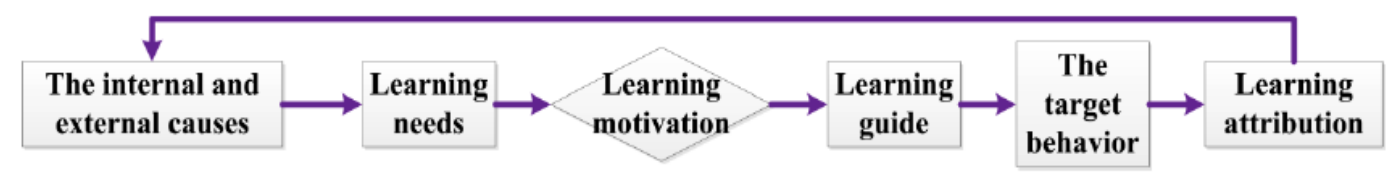

Fig. (1). The motivation management in personal learning environment. 


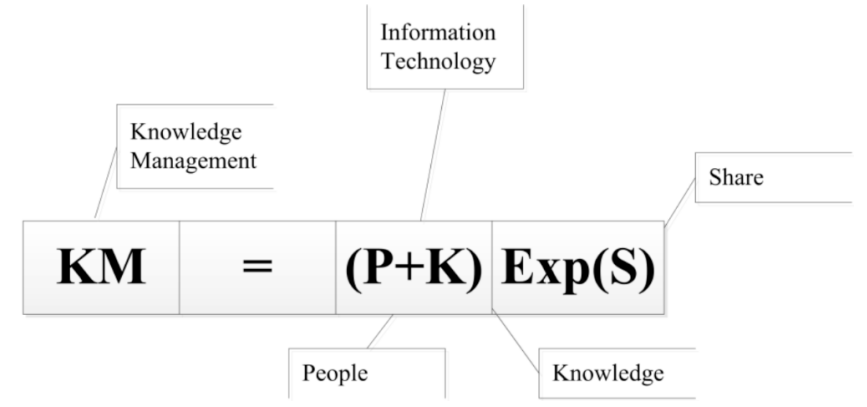

Fig. (2). The formula of knowledge management.

\section{FACTOR ANALYSIS AND FUNCTIONAL CHAR- ACTERISTICS OF PERSONAL LEARNING ENVI- RONMENT}

PLEs is the study of individuals in the knowledge age, according to a new study by Web2.0 and network theory, a variety of social software as technical support, focusing on construct the meaning of knowledge as the center, to find the learning needs, learning pace, self-controlled learning process, and the independent management of the growing experience the adaptive learning system collectively.

\subsection{Tor Analysis of Personal Learning Environment}

We believe that PLEs is a group of six, including six elements, namely: the personal learning environment factors (PS, KG = PLEs, TS, AV, CT, EN), as shown in Fig. (3).

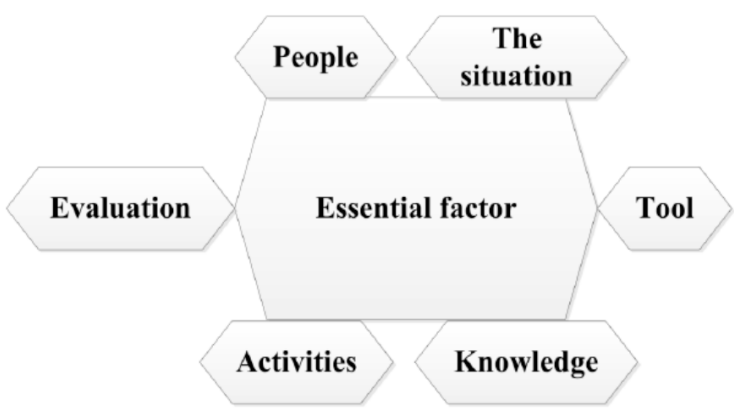

Fig. (3). Elements of personal learning environment.

PS: (person), PLEs is the "human resources", to solve the "who" and "who to learn". Refers to the individual learning (learning main body role), but also includes other individual promotes the main body of learning (such as learning companions, teachers and experts) and study group (study group, such as the interest group and the virtual community and so on).

$\mathrm{KG}$ : is knowledge (knowledge), PLEs is the "learning content library", "what to learn" to solve the problem. The traditional textbooks, books, teaching, practice, practice, training and network, and the others are all valid sources of knowledge.

TS: a tool (tools), PLEs is the "feeding", solve the problem of "what to learn". In addition to the traditional dictionary tools, stationery and library, mainly with Web2.0 technology and the rapid development of all kinds of social software, such as Blog, E-mail, Microblog, Skype, QQ, Mind Manager, MSN, Wiki, Rss and so on.
AV: activity (activity), PLEs is the "soft power - learning method base", to solve the problem of "how to learn", mainly refers to promote learning activities together, it is a change or a combination of various elements of the results. In general, the individual development depends on the various activities of the support, the main form from individual / group / team, independent two dimensions to consider.

CT: namely the situation (context), PLEs is the "base camp", "social support" to solve the problem, mainly refers to the individual learning is not with the practice and context of phase separation, knowledge is in the interaction of individual and environment, and through the legal, marginal participation in construction of social negotiation. Specifically, mainly includes two kinds of situations: one is the existence of the real world situations that support learning (i.e. "learning needs"

The two class problem); in the process of learning the individual should be actively involved in the self, others and the environment, the interaction and the practice situation (i.e. learning "practice field").

EN: evaluation (evaluation), PLEs is the "detection and reflection zone", "learn how to solve problems", mainly through the study of individual learning tool trajectory, the related works are learning to collect evidence, and on the basis of the qualitative and quantitative examination of the relevant evaluation criteria, and ultimately make the value judgment of learning study report, write. At the same time, in particular, need to pay attention to is, we should be based on a comprehensive study of the PLEs report, reflection and practice virtue, in order to achieve the learning convergence, continuity and sustainable development.

\subsection{Functional Characteristics of Personal Learning En- vironment}

The PLEs is a complex system composed of many elements, in such a way that all the "me" in the learning environment, learning of the six elements of what it would be like? Jonathan's meaningful learning is an individual pursuit in the PLEs study, which is the intention and real, active constructive and cooperative meaningful learning. Active: meaningful learning requirements of individual positive initiative in PLEs, on the basis of self-learning needs, learning occurs for the "real" situation, brought together all kinds of tools, take the initiative to integrate into the community, and to observe their operating results. Construction: the individual in learning new knowledge, knowledge of the original will often produce conflict and new knowledge, make individuals feel confused, this confusion is a catalyst for meaning making and adaptation between the old and new knowledge, by continuous assimilation, mental model of individual can slowly to build more and more complex. Purpose: individual learning is always around a certain intention, in PLEs, exactly what to study, what is completely determined by the individual himself. When learning from the heart of true calling, become a great need of self-realization, the individual will truly "active", and for the realization of that intention and spare no effort to. True: PLEs as a new learning form, which is one of the reasons to produce inert knowledge in school education "to try to avoid". Individual learning in PLEs is the real life or self- 
creation based on the real situation, which is not only beneficial to the knowledge of the self-construction of meaning, and the "smart" knowledge can not only solve the preset problems, can work for a living and service. Cooperation: in the PLEs community, is very important for individual learning and growth, cooperative / collaborative learning always occur in the whole learning process. Community cooperative / collaborative learning can not only bring the wisdom of crowds (based on the wisdom of crowds), as a new technology of other special cognitive framework can promote the self-application and update, at the same time, among the members of the conversation can also promote the self-generation and self-cognition.

\section{CONSTRUCTIVIST ENGLISH INDIVIDUAL LEARNING MODEL BASED ON THE SCENE}

This study attempts to apply the PLEs as a complex system of human and environment, scholars at home and abroad on the basis of the existing research results of PLEs, PLEs is selected to study metaphor, to explore how to build a personal learning ecosystem harmony, balance and sustainable development. Since 2004 since the spread of the concept of PLEs, analysis of the concept, PLEs research has been focused on the PLEs components and how to use Web2.0 to build PLEs platform, the lack of construction of the PLEs system from the source to a comprehensive analysis of the research. In our view, although PLEs is personalized and self-customizing, that everyone has their own PLEs, but as "success is the same, but different failure" said, to effective learning in the self-construction of the PLEs, each PLEs construction, have experienced something common, such as learning how to clear and correct understanding of self; how to efficiently process management, such as: the learning situation of the control, interpersonal adjustment and knowledge management; and after learning how to evaluate the effect of self-learning and selfreflection, learning, improve learning and sustainable development etc.

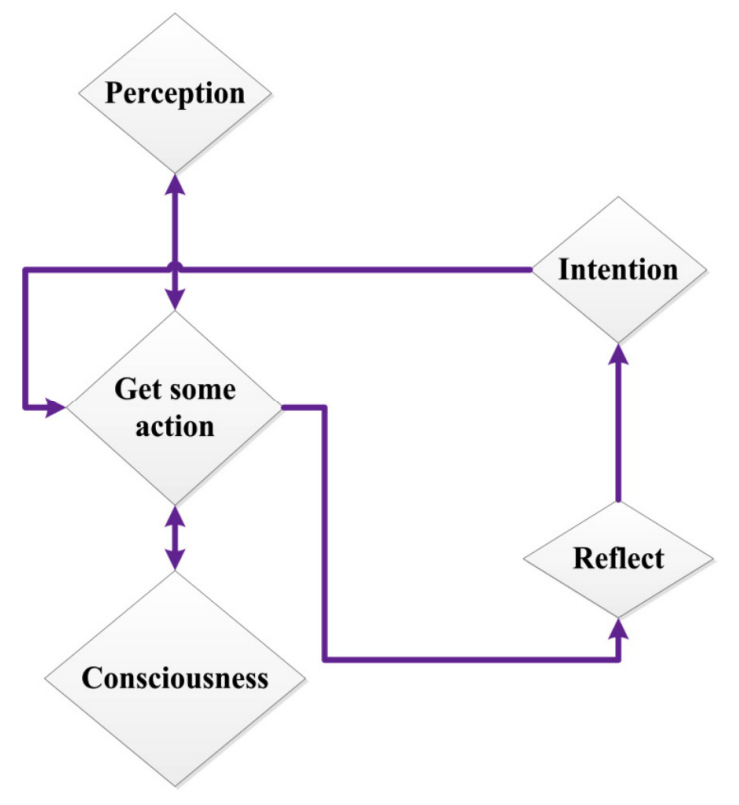

Fig. (4). Action-get some action-reflective learning.

\subsection{The Basic Principles of Model Construction}

\section{A. The Diversity Principle}

In the PLEs, it is by the efficiency factor and factor supplies the "ecological factors" diversity, interaction and coexistence. In the construction of the PLEs process, we should firmly grasp this, for PLEs to inject more new ", to nourishing liquid", for its flow. At the same time, we must understand that, to keep the PLEs diversity is to focus on specific Center (namely the individual learning needs) to matching process diagram, organized and planned, is not a random packing supplies.

\section{B. The Integral Principle}

From the perspective of ecology construction problems down to talk about PLEs, we not only need to separate each of "ecological factor", also want to see the effectiveness of subject, of all the factors of the environment, the so-called "both see the trees, and forest". In PLEs, all kinds of factors are analyzed separately, and make them the whole ecological view, on the one hand is because the single factor effect is limited, only the combination as a whole, in order to further excavate and expand; on the other hand, because of various factors integrated into the overall in a specific way, can play a certain new characteristics and originally does not have the function, realize the innovation of structure and function, and further promote the individual learning.

\section{The Principle of System}

Effect of complex biological and environmental interaction, is an integrated whole, also is a complex system. In the PLEs in the process of the construction, we also need to examine the system concept, pay attention to the system of PLEs. Overall, we emphasize the system, mainly because the PLEs is not only the overall composition of the support elements, it should pay attention to the interaction between the various elements, and knowledge exchange and emotional exchanges outside, and each part of each other's feedback control system, namely under the view of the overall performance of the PLEs.

\section{The Dynamic Principle}

The PLEs is not a function of the whole system and it is continuous, dynamic change. Construction process in PLEs, to grasp the dynamic of this principle, we need to understand that: a) factor is not immutable and frozen components PLEs, some factors will increase with time or decrease, even disappear, such as the rapid development of technology, tool is constantly updated and replaced, web technology is a good example; B) the effectiveness of body in self intention driven, aggregating the supplies factor itself is a dynamic process, and combine them into a system with the overall structure and function, it must make the necessary deployment and management of the process, it is also a dynamic process.

\section{E. The Circulation Principle}

The PLEs is a function of the system, it is not satisfied with the temporary equilibrium, it is the pursuit of a continuation of the function and evolution of permanent. To achieve this aim, we should pay attention to in the process of 
the construction of the PLEs, the cycle of design. Namely: 1 st, to learn to drive the continuous intention, perception -action for the interaction mechanism; 2nd, have the ability to continue from the environmental awareness support action, and put into practice; 3rd, pay attention to feedback regulation system, and make a proper adjustment, in pursuit of the structure and function of further.

\subsection{The Construction of Theoretical Models}

UNESCO International Education Committee of the "learning to be: the world of education today and tomorrow" in one book, the author tells us "the psychology research points out: one is a not fully develop animal, only through continuous lifelong learning, in order to continue to grow, the accumulated precipitation and to improve their". The PLEs had been as a man wise choice for lifelong learning, is not only the effective method to improve and perfect themselves, but also is an important factor affecting individual's comprehensive competitiveness. Therefore, the essence of metaphor in ecology and learning guide for PLEs, with the combination of the above on the PLEs construction process and principles, we explored the theoretical model of PLEs is constructed as shown in Fig. (5).

As shown above, the model tells us: PLEs construction process, can be started from the study of individual "effectiveness" level and the social culture "supplies" level, between driving, in order to promote the knowledge exchange and emotional communication. Direct contact with the circle in two levels, one is that PLEs is continuous between effectiveness and supplies of the two coupling interaction; two is a clear PLEs is a personal learning ecosystem a need to constantly adjust, perfect, in order to achieve the iteration loop and helical structure and function of PLEs on the rise.

"Effectiveness" level, including the self-cognition, perception action and metacognition ability three aspects mainly, namely the individual in the full understanding of self, perceptual learning intention, and with an expression of overt or covert, stimulate or guide a certain behavior, the effectiveness of subject in the environmental awareness of the possibility of surrounding supplies, implementation the appropriate action at the same time, through the perception action and self-cognitive metacognitive reflection, adjustment and improvement, to achieve a comprehensive understanding of the "effectiveness" layer and grasp.

"Provision" level, mainly refers to the environmental provisions factor, artificial products (tools), interpersonal network (learning / communities of practice and social context (background) the real social support) and carrying on of the three knowledge and three learning activities based on the combination of. In addition to individual learning, the outside world that support learning conditions are catering, property belonging to the specific environment. Catering environment is objective existence, not the people's will, the learning ability of detecting individual perception -- action required to implement the provisions, and the smooth construction of PLEs with them, mainly depends on the effectiveness of the breadth of subjects (multi ability) and depth (a specific capacity of proficiency), namely the individual effectiveness and environmental supplies between the matching problem.

From the overall perspective, PLEs is "coupling interaction process performance" and "provisions" of the construction level, PLEs is to generate the individual learning ecosystem. Successful learners have a clear understanding of self-efficacy, matching, combination of activities have been carried out him or her in action in the ecological system of personal supplies, supplies the overall effectiveness -- cyclic process will continue to push the learning goals, performance subject and catering environment also often provide evaluation toward the goal of learning situation and feedback, timely detection and treatment of a variety of learning crisis, to achieve individual learning ecosystem diversity coexist, dynamic balance and circulation evolution state.

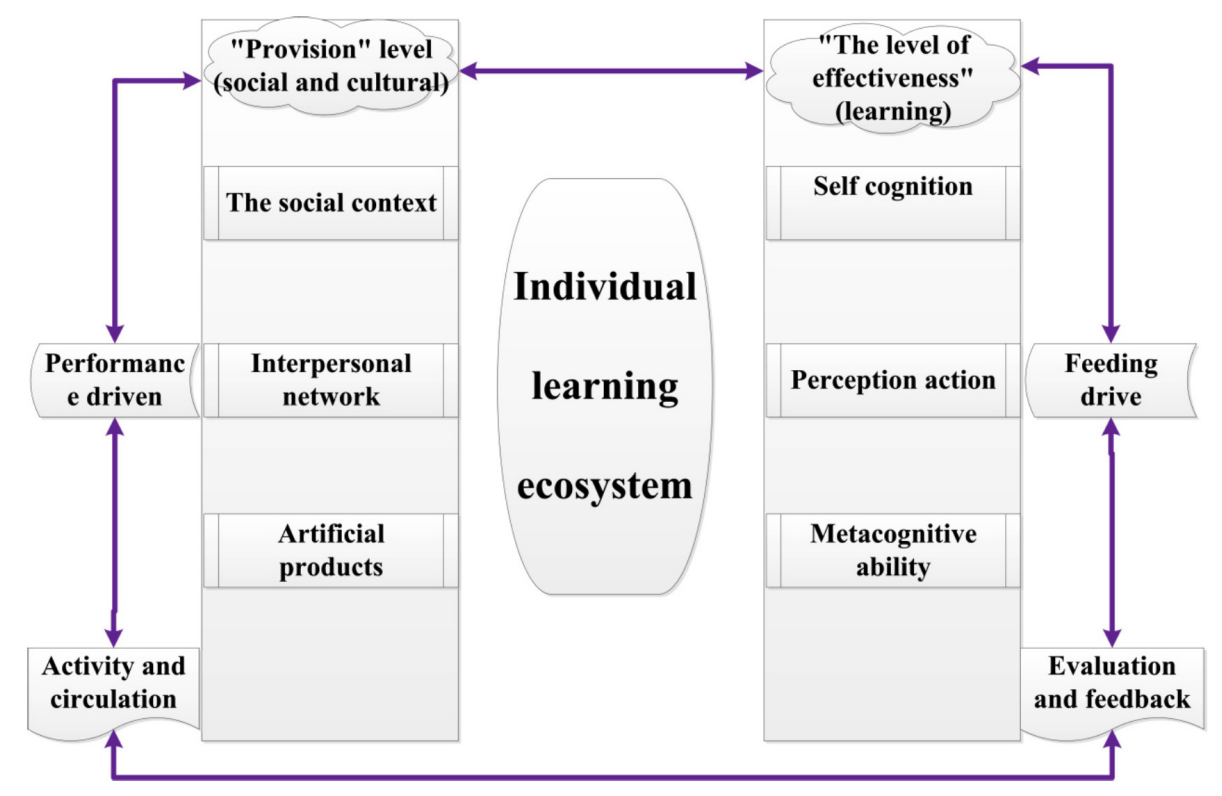

Fig. (5). The model. 


\subsection{The Analysis Model of the Enlightenment}

In summary, through the research of the model, we can clearly see: PLEs constructed the theoretical model and the specific strategies, in specific construction practice, there is a similar process. Therefore, the results of this research have practical support, has the scientificalness and rationality. But in practice, we should pay attention to the following points:

A, the PLEs proposed in this paper to construct, but highly generalization of the construction process, such as a model of the role of the general, it is that we have to grasp an overall construction of PLEs macro thinking, can't and does not need to show the entire contents of PLEs construction. This is also the starting point of the model proposed in this paper, such as the Tom PLEs construction practice, only reflects the main content of the model.

$\mathrm{B}$, the model proposed in this paper based on the PLEs, to explore the specific strategies to the construction of the. The successful experience of case study as the Tom show, it is only in the proposed strategy, rather than as like as two peas. Therefore, the construction of PLEs in this study is just a specific strategies on the construction of personal guidance, self PLEs in construction, can be considered from these aspects, but also have certain aspects, especially a lot of "you have me, I have you" is the process of the intertwined relationship, such as tools, and knowledge is so personal it is not dogmatic, copying, machinery, which is based on the self-reference situation, proper application.

$\mathrm{C}$, as the eyes of one thousand individuals have the same one thousand Hamlett, PLEs construction is a very personalized process, such as in the exchange of the author and Tom, we will make an analogy, namely PLEs construction such as personal home page "set", there is no fixed results, completely according to the needs and self in order to fit their own, as the highest purpose. Therefore, this study is hope for individual PLEs construction enlightenment.

\section{CONCLUSION}

In the phenomenon of informal learning to become normal today, PLEs it can effectively meet the new demands of individual digital learning, learning new successfully meet the challenges of the era of knowledge, to realize "I learn, I call the shots", and now have become much more important form of learning the individual to achieve selfgrowth and occupation development. PLEs as a new learning concept, its future development trend, and the traditional formal learning and informal learning the relationship between the effective support of many theoretical and practical problems need further exploration, such as how to use the mobile phone to achieve efficient mobile learning, micro strategy of the effective interaction in PLEs, in the future research we will be given the close attention and exploration, in order to further improve the subject. Finally, although this study with some questions at the end of the paper, some ideas of is still in the immature stage, the related work is not comprehensive and complete, but I still hope this for more than a year of research and the thesis can provide some ideas for inspiration or reference value for the research and practice of PLEs.

\section{CONFLICT OF INTEREST}

The author confirms that this article content has no conflict of interest.

\section{ACKNOWLEDGEMENTS}

Declared none.

\section{REFERENCES}

[1] G. Attwell, "Personal learning environments-the future of elearning," e-Learning Papers, vol. 2, no. 1, pp. 1-7, 2007.

[2] S.R. Sankaran, and T. Bui, "Impact of learning strategies and motivation on performance: A study in web-based instruction", Journal of Instructional Psychology, vol. 28, no. 3, p. 191, 2001.

[3] D. Jonassen, K. Peck, and B. Wilson, "Learning with Technology: A Constructivist Perspective," Prentice Hall, Canada, 1999.

[4] D. Jonassen, "Supporting communities of learners with technology: a vision fo integrating technology with learning in schools," Educational Technology, vol. 7/8, pp. 60-63, 1995.

[5] R. T. Kompen, P. Edirisingha, and R. Mobbs, "Building web2.0based personal learning environments-a conceptual framework," In: Proceedings of EDEN Research Workshop, Paris, 2008.

[6] Y. Hu, Listened to the Balance of the Ecological System. The Network Construction of, Nanjing Forestry University, Nanjing, vol. 4, 2008.

[7] J. Rick, Y. Rogers, C. Haig, and N. Yuill, "Learning by doing with shareable interfaces", Children Youth and Environments, vol. 19, no. 1, pp. 320-341, 2009.

[8] Z. Zhong, The Innovation Teaching Mode, University Teaching Design from the Perspective of Beijing, Educational Science Publishing House, Beijing, 2008.

[9] S. Xu, Knowledge of University Students in the Era of Personal Learning Environment Construction Research, Jiangxi Normal University, China, vol. 1, no. 7, pp. 41, 2010.

[10] H. Zhang, "Bu color beauty. On the study of ecological system," China Distance Education, vol. 4, pp. 23-26, 2007.

[11] M. Lee, Technology and Learning -- On Learning Information, Science Press, Beijing, 2007.

[12] G. Attwell, "Personal learning environments-the future of eLearning?", Elearning Papers, vol. 2, no. 1, pp. 1-8, 2007.

[13] W. Hong, Web2.0 PLE Model Based on the Creation of Research, Jiangxi Normal University, China, 2009.

[14] W. Na, The Network Learning Environment of the Ecological Crisis and the Countermeasures Research, Hebei University, Hebei, 2010.

[15] P. Baxter, and S. Jack, "Qualitative case study methodology: Study design and implementation for novice researchers", The Qualitative Report, vol. 13, no. 4, pp. 544-559, 2008. 